\title{
Optimization of operating parameters by SEM in HVOF deposition of $\mathrm{NiCr}$ coatings
}

Sergio Sauceda Martínez ${ }^{1}$, Jaime Núñez Segovia ${ }^{1}$, Carolina Parra González ${ }^{2}$, Luis Bejar Gómez ${ }^{3}$ and Sheila Lascano Farak ${ }^{4}$

${ }^{1}$ Universidad Técnica Federico Santa María, Region Metropolitana, Chile, ${ }^{2}$ Universidad Técnica Federico Santa María, Valparaiso, Chile, ${ }^{3}$ Universidad Michoacana de San Nicolás de Hidalgo, Michoacan de Ocampo, Mexico, ${ }^{4}$ Universidad Técnica Federico Santa María, Valparaiso, Region Metropolitana, Chile

Hard coatings are used to provide greater resistance to wear, corrosion and reduce friction. Those deposited by HVOF (High-Velocity Oxyfuel) technique produce highly adherent coatings, with low porosity $(<5 \%)$ and high hardness [1]. However, few studies allow the optimization of HVOF application parameters for $\mathrm{NiCr}$ based coatings on steels which are widely used in the manufacturing industry [2]. This study proposes the deposition of Cr3C2-NiCr coatings by HVOF deposited on AISI 4140 steel to generate thick high-quality coatings with low porosity and high hardness and adhesion. For this work, changes in HVOF gun speed (5 and $15 \mathrm{~mm} / \mathrm{s}$ ) were studied due to its influence on the application time. In addition, roughness of the substrate before application of the coating (55 and $85 \mu \mathrm{m}$ in $\mathrm{Rz}$ ) was took into account, since it has a strong relationship with final mechanical properties [3].

The characterization of the powders and the thickness of the coatings applied by HVOF were carried out using a Field Emission Scanning Electron Microscope (FE-SEM) equipped with an Energy Dispersive X-ray Spectrometry (EDS) probe. Images of the powder (Figure 1) were obtained at $20 \mathrm{kV}$ under vacuum conditions using secondary electrons (SE). The cross-section of the samples was studied by FE-SEM using backscattered electrons (BSE), allowing to identify the different elements present in the coating, to differentiate phases and to study the interface and the substrate in a clear way. Line-scan analysis were also performed to evaluate substrate and coating composition, aiming to verify that this thermal spray coating process does not cause diffusion that might modify the base substrate's elemental composition.

Two main phases, $\mathrm{NiCr}$ and $\mathrm{Cr} 3 \mathrm{C} 2$, were observed in the powdered state, as well as in the deposited coating, keeping an homogeneous distribution in all cases. The $\mathrm{NiCr}$ and $\mathrm{Cr} 3 \mathrm{C} 2$ agglomerates in the deposited coating can be identified as light grey and dark grey zones respectively, as shown in Figure 2. A less abundant third phase, attributed to $\mathrm{Cr} 7 \mathrm{C} 3$ and $\mathrm{Cr} 23 \mathrm{C} 6$, was found in some deposited coatings. According to our results the coatings deposited using $15 \mathrm{~mm} / \mathrm{s}$ gun speed on a $85 \mu \mathrm{m}$ rough surface (Figure 2a) exhibited higher porosity $(>2 \%)$ and lower thickness $(39 \mu \mathrm{m})$ when compared to the coating deposited using $5 \mathrm{~mm} / \mathrm{s}$ gun speed on a $55 \mu \mathrm{m}$ rough surface (Figure $2 \mathrm{~d}$ ), that presented $273 \mu \mathrm{m}$ thickness and $<1.5 \%$ porosity. It was found that substrates with lower roughness generate coatings with higher thickness, lower porosity and the presence of less zones with unmelted particles, when compare with coatings that presented higher roughness. These coating features (low roughness, higher thickness and lower porosity) are critical for the coating to present better cohesion and adhesion to the substrate. Changes of the gun speed do not show significant effects on the quality of the coatings.

According to line-scan analysis, the intersection between the coating and the substrate presents an abrupt section change, produced by an important drop in $\mathrm{Cr}$ and $\mathrm{Ni}$ levels characteristic of the coating and the rise in Fe levels that marks the beginning of the substrate (Figure 2). This indicates that the process temperature is not high enough to produce diffusion between the coating and the substrate. For the coating section it was also found that nickel levels increase when Cr levels drop. This is presumably due to the presence of both the matrix and carbide phases well defined. 

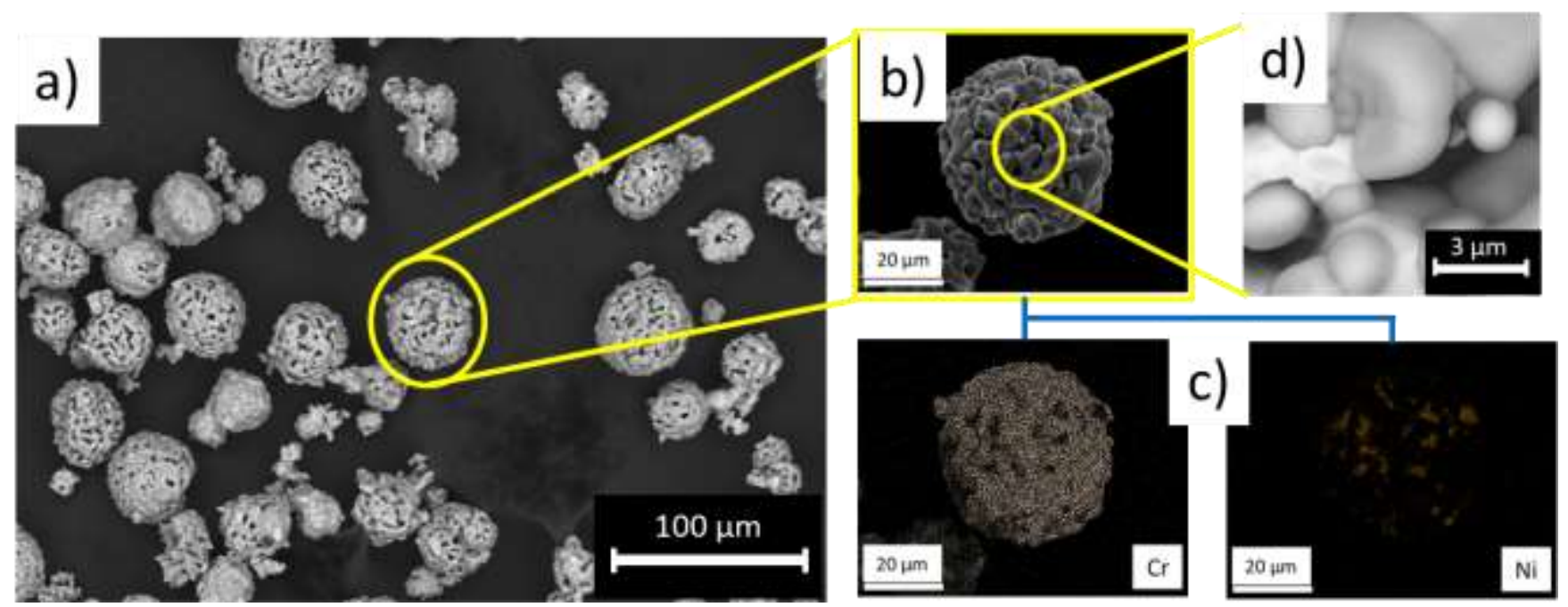

Figure 1. Figure 1. SEM images of Cr3C2-NiCr powder a) 1000x, b) 5000x c) EDS at 5000x and d) 30000x.

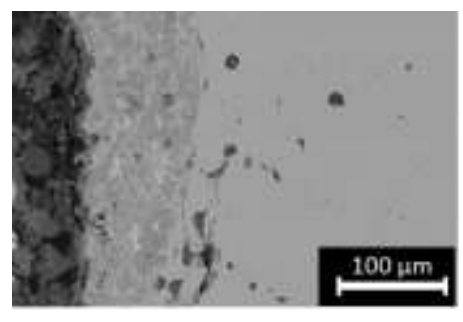

a)

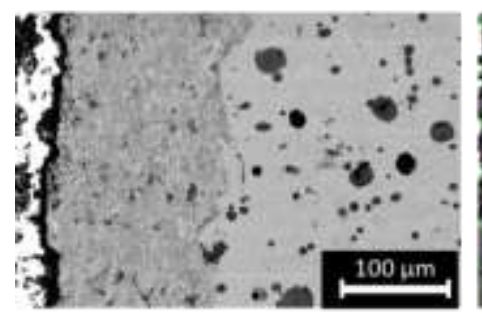

c)
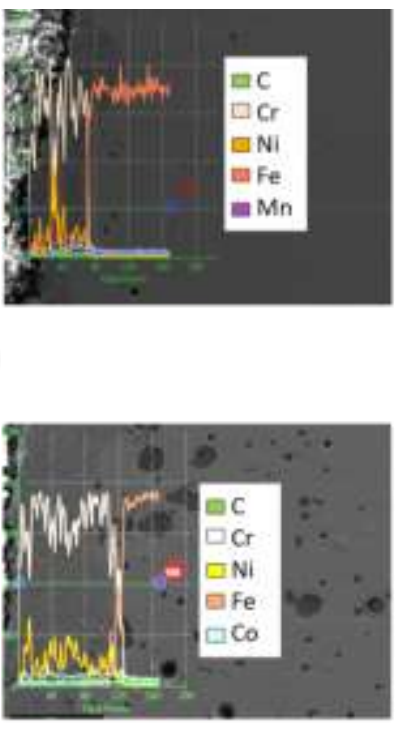
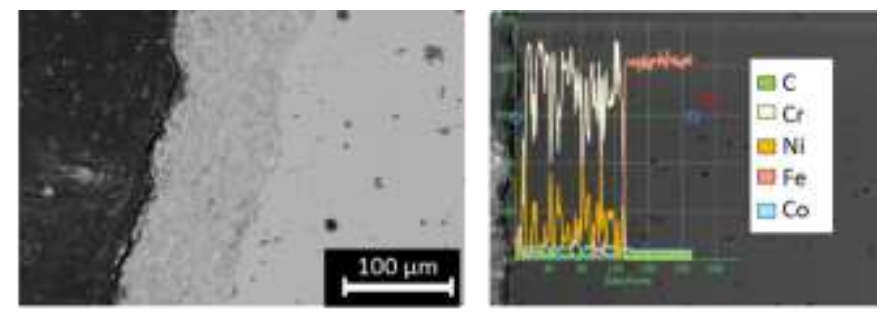

b)
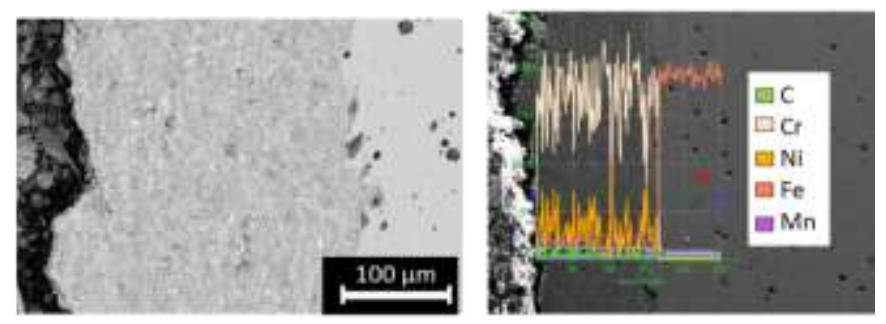

d)

Figure 2. Figure 2. SEM images and EDS line-scan analysis of coatings at 1000x, a) with $15 \mathrm{~mm} / \mathrm{s}$ and 85 $\mu \mathrm{m}$ in Rz, b) $5 \mathrm{~mm} / \mathrm{s}$ and $85 \mu \mathrm{m}$ in Rz, c) $15 \mathrm{~mm} / \mathrm{s}$ and $55 \mu \mathrm{m}$ in Rz and c) $5 \mathrm{~mm} / \mathrm{s}$ and $55 \mu \mathrm{m}$ in Rz.

\section{References}

[1] G. Bolelli, et al, Wear. vol 450 (2020), p. 203273.

[2] D. Poirier, J.-G. Legoux, R.S. Lima, Journal of thermal spray technology, 2013, vol. 22, no 2-3, p. 280289.

[3] Bolelli, et al, Surface and Coatings Technology, 2006, vol. 200, no 9, p. 2995-3009. 